\title{
O déspota e os escravos: a alteridade brasileira na independência do Uruguai (1821-1828)
}

\author{
The despot and the slaves: the brazilian's alterity \\ in the independence of Uruguay (1821-1828) \\ El déspota y los esclavos: la alteridad brasileña \\ en la independencia del Uruguay (1821-1828)
}

Murillo Dias Winter ${ }^{\mathrm{a}}$

\begin{abstract}
Resumo: A independência do Brasil possibilitou novos arranjos políticos na Província Cisplatina, território em disputa desde o período colonial entre os impérios ibéricos e, posteriormente, entre as forças brasileiras e buenairenses na Guerra da Cisplatina. Nessa complicada relação entre diversos grupos, identidades e alteridades, o conflito entre Brasil e as Províncias Unidas do Rio da Prata, possibilitou a emergência de novos elementos de diferenciação e identificação ligados aos dois principais envolvidos na contenda, todavia, principalmente, colocou em evidência a orientalidade herdada de José Gervásio Artigas, nesse momento abrangendo todo o território, inclusive a capital Montevidéu, elemento fundamental no posterior discurso de legitimação da Nação independente da República Oriental do Uruguai, que proponho, teve no Brasil um importante contraponto e elemento de diferenciação externa e aproximação interna. Elementos a serem analisados no presente trabalho.
\end{abstract}

Palavras-chave: Alteridade. Brasil. Guerra da Cisplatina.

Abstract: The independence of Brazil allowed new political arrangements in the Province Cisplatin, disputed territory since the colonial period between the Iberian empires and, later, between Brazilian forces and buenairenses in the Cisplatine War. This complicated relationship between different groups, identities and alterities, the conflict between Brazil and the United Provinces of the River Plate, made possible the emergence of new elements of differentiation and identification attached to the

\footnotetext{
${ }^{a}$ Graduado e mestre em história pela Universidade de Passo Fundo (UPF). Doutorando em História Social pelo Programa de Pós-Graduação em História Social da Universidade Federal do Rio de Janeiro (PPGHIS-UFRJ). Esta pesquisa contou com o financiamento da Coordenação de Aperfeiçoamento de Pessoal de Nível Superior (CAPES).<murillodiaswinter@hotmail.com>.
} 
two principals involved in the feud, however, mainly highlighted the orientality José Gervasio Artigas inherited, this time covering the entire territory, including the capital Montevideo, key element in further legitimizing discourse of the independent nation of the Republic of Uruguay, I propose, in Brazil had an important element of counterpoint and external differentiation and internal approach. Elements to be analyzed in this work.

Keywords: Alterity. Brazil. Cisplatine War.

Resumen: La independencia e Brasil ha posibilitado nuevos arreglos políticos en la Provincia de la Cisplatina, territorio disputado desde el período colonial entre los imperios ibéricos $\mathrm{y}$, después por las fuerzas brasileñas y bonaerenses en la Guerra de la Cisplatina. En esta intricada relación entre diversos grupos, identidades y alteridades, el conflicto entre Brasil y las Provincias Unidas del Río de la Plata, posibilitó la emergencia de nuevos elementos de distinción e identificación de los principales implicados en la disputa, sin embargo y ante todo, ha puesto en evidencia el orientalismo heredado de José Gervasio Artigas, en ese momento correspondía a todo el territorio, incluso la capital Montevideo, elemento fundamental en el posterior discurso de legitimidad de la nación independiente de la República Oriental del Uruguay, a lo que propongo, tuvo en el Brasil un importante contrapunto siendo elemento de distinción externa y acercamiento interno. Elementos que serán analizados en el presente texto.

Palabras clave: Alteridad. Brasil. Guerra de la Cisplatina.

\section{Identidades e alteridades: a Província Cisplatina em disputa}

No texto, integrante da coleção Memória do fogo, intitulado A pátria ou a tumba, Eduardo Galeano ironicamente destaca a arte pretensamente desengajada de Francisco Acuña de Figueroa. ${ }^{1} \mathrm{O}$ alvo é a alternância de posições e compromissos do autor, de grande produção literária, mas conhecido, principalmente, pela composição do Hino Nacional da República Oriental do Uruguai:

\footnotetext{
${ }^{1}$ Francisco Acuña de Figueroa (1791-1862) nasceu e faleceu em Montevidéu. Com formação clássica, de difícil acesso no período e na Banda Oriental, se destacou nas letras. O Guia de autores uruguaios o define da seguinte forma: Fue, en su época, "el poeta de Montevideo", de sus avatares, de sus mandatarios y de las personas de relevancia en aquella sociedad. Cronista en verso de los episodios más dramáticos, registró los acontecimientos, día a día, del Segundo Sitio de Montevideo y fue autor del Himno Nacional uruguayo y de otros himnos; tradujo obras clásicas y contemporáneas, incorporó formas y ritmos populares, compuso poemas visuales, epigramas, anagramas, acrósticos en los que celebra, entre loas y burlas, una gran variedad de estampas. Describió su caudalosa producción como compuesta por piezas Patrióticas, Amatorias, Fúnebres, Jocosas, Religiosas, Ingeniosas, Enigmáticas, Varias, Epigramáticas y Satíricas, sin contar aquellas que excluyó, ocultó y olvido. In: <http://www.autoresdeluruguay.uy/biblioteca/ francisco_acuna_de_figueroa/>.
} 
O primeiro vate do parnaso uruguaio, Francisco Acuña de Figueroa, iniciou-se nas letras compondo uma ode, em oitavas reais à glória militar da Espanha. Quando os gaúchos de Artigas tomaram Montevidéu, fugiu para o Rio de Janeiro. Lá brindou suas rimas de louvor ao príncipe português e a toda sua corte. Sempre com a lira no ombro, dom Francisco voltou para Montevidéu seguindo os invasores brasileiros, e tornou-se poeta das tropas de ocuaiupação. Anos depois, no dia seguinte da expulsão das tropas brasileiras, as musas sopraram patrióticos decassílabos ao ouvido de dom Francisco, louros de palavras para cingir as frontes dos heróis da independência; e agora o reptilíneo poeta escreve o hino nacional do país recém-nascido. Nós, os uruguaios, somos obrigados para sempre a escutar seus versos em pé. (Galeano, 2010. p. 210)

Abstraindo os juízos de valor, o texto revela características marcantes das primeiras décadas do Oitocentos: a fluidez das identidades, a pluralidade de alternativas políticas em jogo e a ausência de rígidos recortes nacionais ou, ao menos, formas estritas de identificação nacionalista. Conforme essa perspectiva, a proposta deste ensaio é indicar elementos para a compreensão de como o Brasil, juridicamente e militarmente de posse da Província Cisplatina ${ }^{2}$, é retratado pela imprensa local e, então, indicar a construção de uma alteridade brasileira que pode ter sido decisiva no reconhecimento mútuo dos habitantes da região e no processo de construção identitária de um Uruguai independente, próximo de Buenos Aires e distante do Império do Brasil.

Estabelecidos na região desde a ocupação em 1817, os brasileiros são grande parte da Província Cisplatina, principalmente da elite montevideana, durante a ocupação de Portugal, graças ao vislumbre de uma parcial liberdade com os movimentos constitucionalistas no reino lusitano e ao apoio local oriundo do fantasma do período anterior de guerra civil. Com a cisão das tropas lusitanas e a independência do Brasil, o grupo passa a sofrer maior oposição, e a administração de Carlos Frederico Lecor (1764-1836), comandante da região desde a intervenção militar de 1816 , é contestada até mesmo pela classe dirigente, antes apoiadora do general. A projeção de uma independência

\footnotetext{
${ }^{2}$ Sob posse oficial de Portugal, que tinha intervindo militarmente em 1816, a partir de $1821 \mathrm{com}$ o Congresso Cisplatino e posteriormente do Brasil, a região não tinha limites territoriais precisos e durante o período colonial, sob a nomenclatura de Banda Oriental do rio Uruguai, marcava espaço de fronteira entre os domínios lusitanos e espanhóis, possuía como demarcações geográficas o rio da Prata, o rio Paraná ou o próprio rio Uruguai. Ver: ISLAS, Ariadna. Límites para un Estado. Notas controversiales sobre las lecturas nacionalistas de la Convención Preliminar de Paz de 1828. (Frega, 2011, p. 174).
} 
na região passa a ser cogitada, e a presença imperial é determinada como despótica e ilegal.

É nesse sentido que na edição de número oito do periódico é $E l$ Ciudadano publicado um texto contendo Observaciones sobre la carta del traidor Fructos Rivera al Cabildo de Montevideo. Ainda que não tenha sido possível averiguar o conteúdo da carta escrita por Fructuoso Rivera (1784-1854) as observações indicam importantes caminhos para compreender os diferentes projetos políticos que coexistiam na Província Cisplatina e as relações entre identidades e alteridades que alicerçavam ideias de futuro e de construção de novos corpos políticos ainda indefinidos. Desse modo, a alteridade Brasiliense é ponto fundamental da diferenciação entre os locais, os vizinhos platinos, as tropas de ocupação e o projeto unitário de Santiago Vázquez, redator do El Ciudadano que defendia a integração de todo Prata apenas sob um governo. Para Vázquez, embora a guerra civil e a consequente ocupação luso-brasileira para a suposta pacificação da região tenham transmitido a impressão de conformidade com a anexação da Banda Oriental sob o título de Província Cisplatina, e posteriormente, os movimentos do Cabildo ${ }^{3}$ de Montevidéu conduzissem os sentimentos de uma luta pela independência total da região, nenhum destes dois projetos se adequariam ao real desejo da maioria da população local, visto que estes eram partidários de uma independência parcial, ou seja, livrar-se da ocupação estrangeira para unir-se às Províncias Unidas do Rio da Prata. Portenhos e Orientais além dos costumes em comum, também compartilham a americanidade de quem lutou pela independência e buscava construir um governo liberal e republicano escolhida pela população em um pacto político, enquanto o Brasil representaria uma união aristocrática, violenta e opressora:

pero aun en medio del furor y extravios de ella [Guerra Civil], ni la parte mas sensata, ni las maximas de su gobierno, ni el voto general de los habitantes estuvieron por la absoluta desmenbracion, sino por esa independencia relativa que por los mismos principios que el autor acomoda en la confederación del imperio es perfectamente adaptable y mucho mas conforme en otra confederacion no imperial, no violenta, no repugnante, sino apoyada en las bases que ha sancionado la ilustracion del siglo, arreglada á principios liberales y acomodada á las antiguas relaciones, hábitos, costumbres $\&$ de nosotros los americanos del rio de la plata y no brasilienses. (El Ciudadano. Montevidéu, $\mathrm{n}^{\circ}$ 08, 20 de julho de 1823)

\footnotetext{
${ }^{3}$ Unidade administrativa municipal no mundo colonial hispânico, onde a população local tinha representatividade jurídica e política imediata.
} 
O desenvolvimento de identidades coletivas plurais, em processo de politização, na mesma territorialidade, como observado no trecho citado, não é exclusiva da Província Cisplatina, o mesmo ocorria no restante da América portuguesa (Jáncso; Pimenta, 2000) e da América espanhola (Chiaramonte, 1989). O caso cisplatino denota a aproximação dessa região como ponto de intercessão e de ligação do que antes foi o mundo colonial ibero-americano, implicando na coexistência e redefinição de identidades em um espaço de conturbação política e social, onde haviam interesses e influências de ambos os lados, de fala hispânica ou de língua portuguesa. A melhor definição da importância dessas identidades na crise do Antigo Regime e suas projeções para o futuro, geralmente associando-se a algum projeto nacional é de István Jancsó e João Paulo Pimenta ao afirmarem que a coexistência

de múltiplas identidades políticas, cada qual expressando trajetórias coletivas que, reconhecendo-se particulares, balizam alternativas de seu futuro. Essas identidades políticas coletivas sintetizavam, cada qual a sua maneira, o passado, o presente e o futuro das comunidades humanas em cujo interior eram engendradas, cujas organicidades expressavam e cujos futuros projetavam. Nesse sentido, cada qual referia-se a alguma realidade e a algum projeto de tipo nacional. portuguesa. (Jáncso; Pimenta, 2000, p. 132)

É importante, contudo, destacar que a identidade Oriental, suas aproximações e distanciamentos dos portenhos e a negação irrestrita da dominação brasileira não compunham os únicos projetos políticos presentes na Província Cisplatina (Barrán; Frega; Nicoliello, 1999), entretanto eram os mais importantes e cujos atores integravam os esforços políticos e sociais com vistas ao futuro da região, arregimentando grupos de menor expressão com objetivos afins. Nessa complicada relação entre diversos grupos, identidades e alteridades, o conflito entre Brasil e as Províncias Unidas do Rio da Prata, possibilitou a emergência de novos elementos de diferenciação e identificação ligados aos dois principais envolvidos na Guerra da Cisplatina (1825-1828), todavia, principalmente, colocou em evidência a orientalidade herdada de José Gervásio Artigas (1764-1850), nesse momento abrangendo todo o território, inclusive a capital Montevidéu, elemento fundamental no posterior discurso de legitimação da Nação independente da República Oriental do Uruguai, que proponho, teve no Brasil um importante contraponto e elemento de diferenciação externa e aproximação interna. 


\section{Brasil: a construção da diferença}

Com o objetivo de decidir o futuro da Banda Oriental, sob dominação portuguesa desde a derrota definitiva de José Gervásio Artigas na Batalha de Tacuarembó em 1820, foi aberto o Congresso Cisplatino no dia 15 de julho de 1821. Após três dias de deliberações os doze deputados, sob a égide e a influência de Carlos Frederico Lecor, Barão de Laguna, por unanimidade determinam a oficialização da ocupação lusitana da antiga Banda Oriental pelo Reino Unido de Portugal, Brasil e Algarves. Após a votação as deliberações continuaram, a nomenclatura da nova província e seu governante foram decididas posteriormente, até que no dia 31 de julho foi emitida a declaração oficial de incorporação (Ribeiro, 2007). No dia 5 de agosto, data de encerramento do Congresso Cisplatino, foi realizada a cerimônia de posse com a presença dos congressistas, de Lecor, que permaneceu como comandante da região, e de todos os funcionários do Cabildo de Montevidéu, principal ponto administrativo da agora Província Cisplatina. Ainda no mesmo ano surge o primeiro periódico cisplatino, El Pacifico Oriental de Montevideo, que em citação já utilizada anteriormente, apresenta as benesses da ocupação:

Fijar los límites de nuestros deberes y derechos; enseñarnos à ser libres, y conducirnos à la felicidad son inestimables beneficios: hacernos gozar sin interrupcion de libertad, seguridad y propiedad, y asegurarla para nuestras generaciones futuras, es perpetuar la memoria del justo, nosotros podríamos llegar à esta cima de prosperidad si electrizado el espíritu público, ó menos indolente cortase radicalmente los abusos que en su juicio se oponen à nuestra regeneracion. (Pacifico Oriental de Montevideo. Montevidéu, $n^{\circ}$ 03, 05 de janeiro de 1822)

As referências a Portugal, com maior frequência, e ao Brasil, em menor grau, são ainda tomadas genericamente, nesse contexto de fixação das bases da oficialização da ocupação de Portugal na Província Cisplatina e de mudanças políticas no centro da monarquia portuguesa revelam aspectos positivos e a aceitação dos locais, considerando a elite cooptada pelo Barão de Laguna, quanto à intervenção estrangeira na região. A política e as armas de Portugal, passando pelo Rio de Janeiro e pelas fronteiras de São Pedro do Rio Grande do Sul, são vistas como necessárias para a recuperação de uma região que viveu uma década de conflitos internos e externos e, nesse momento, não possuiria bases 
econômicas e políticas para conseguir se recuperar sozinha. Desse modo, reverberando o típico discurso da regeneração portuguesa, os habitantes da Província Cisplatina, com a pacificação, teriam assegurada a sua liberdade, a sua segurança e a prosperidade econômica. Contudo, o redator do Pacifico Oriental de Montevideo, Francisco de Paula Pérez, não considerava a região como parte integrante do mundo lusitano, embora momentaneamente o fosse. Uma das demonstrações dessas distinções está na separação entre as notícias oriundas de periódicos do Brasil e as publicações locais, o que segundo João Paulo Pimenta "demonstra a ausência de referências políticas claras, no lugar das quais emergem idéias extremamente genéricas", diferenciando-se tanto de portugueses, quanto de brasileiros e embora concordasse com a pacificação, continua mantendo a ideia da orientalidade como identificação dos locais e da alteridade com os dominadores estrangeiros. Nesse ponto a aproximação com Portugal e a necessidade de auxílio externo no desenvolvimento da região, apontam para uma relação e um pacto de sentidos políticos do que a rasgos identitários ou patrióticos para os projetos de futuro dos locais:

Ya estará vd. convencido que en Montevideo hai liberdad de imprenta y para corroborar esta verdad decimos. Que los portugueses y los orientales conocen su situacion perfectamente. mucho mas los primeros que tienen de seguir el curso de su revolucion. asi es que han convenido en unirse intimamente tanto americanos como europeus siempre que su gobierno sea tan liberal como ambas partes quieren: y hay entre ellos hombres que dicen que no volverán á su país si volviese a ser gobernado por la plaga despótica. (Pacífico Oriental de Montevideo. Montevidéu, $\mathrm{n}^{\circ}$ 11, 02 de março de 1822)

Ao longo do ano de 1822 essa diferenciação é ampliada, principalmente quando os eventos do Rio de Janeiro passam a receber destaque especial na imprensa da Província Cisplatina. A principal preocupação estava na possibilidade de ruptura entre Portugal e algumas províncias brasileiras. Na edição de número seis do Pacífico Oriental de Montevideo, publicada no dia 26 de janeiro de 1822, foi comentada, a partir de impressos oriundos fluminenses, a situação política brasileira: "divulgada en los papeles públicos que de allí llegaban, encendieron en el ánimo de los brasileros el amortiguado fuego de la libertad." (Pacífico Oriental de Montevidéu. Montevidéu, n06, 26 de janeiro de 1822). Segundo o periódico, a posição era compartilhada por inúmeros habitantes, visto que "ella se derramó inmediatamente en todos los 
corazones con mas ó menos esplocion à proporción de los obstáculos que encontraba." (Pacífico Oriental de Montevidéu. Montevidéu, n. 06, 26 de janeiro de 1822). Contudo, duas províncias em especial eram as mais exaltadas: "Las provincias del Pará y de la Bahia fueron las primeras que enarbolaran el estandarte." (Pacifico Oriental de Montevidéu. Montevidéu, $\mathrm{n}^{\circ}$ 06, 26 de janeiro de 1822). Após as primeiras notícias veiculadas em Montevidéu sobre as relações tensas entre Lisboa e as províncias brasileiras, prognósticos passaram a ser realizados. Em fevereiro de 1822, foi reconhecida a possibilidade de independência do Brasil, contudo, se esta fosse realizada, a nação deveria permanecer monarquista: "El Brasil, Señor, no puede conservarse yá sin las prerrogativas de Corte, ó al menos sin un ramo de la augusta casa real , que sirva como de centro y apoyo à sus gobiernos provinciales." (Pacifico Oriental de Montevidéu. Montevidéu, $\mathrm{n}^{\circ}$ 07, 02 de fevereiro de 1822). E ninguém mais apropriado que D. Pedro para a Coroa: “¿y cual otro podrá ser él, sino el príncipe inmediato sucesor de la corona, que por este medio se habilita mas para conocer la estension, recursos y precisiones de sus vastos dominios?" (Pacifico Oriental de Montevidéu. Montevidéu, $\mathrm{n}^{\circ}$ 07, 02 de fevereiro de 1822).

O mesmo periódico é o primeiro a examinar o futuro da Província Cisplatina a partir da emancipação brasileira, caso esta fosse concretizada. Francisco de Paula Pérez, questiona: ¿Y qué nos haremos en tales circunstancias, me preguntais? ¿desunirnos de la causa que hemos seguido voluntariamente, y hasta con algunos esfuerzos, $\mathrm{y}$ derramamiento de sangre? ¿quebrantar el juramento que prestamos? (Pacífico Oriental de Montevidéu. Montevidéu, $\mathrm{n}^{\circ}$ 06, 26 de janeiro de 1822). Essas são as dúvidas que seguem principalmente nos meses finais de 1822 e em 1823, fase agudizada dos conflitos pela independência do Brasil na província, e momento visualizado por alguns redatores cisplatinos como oportuno para trabalhar pela liberdade da região. Nesse sentido, foram publicados nas páginas do periódico intitulado La Aurora críticas diretas à dominação agora brasileira e, assim, foi determinado o objetivo dos seus redatores: "El [desejo] de la independencia es el único que aníma á todo el vecindario de la provincia." (La Aurora. Montevidéu, $\mathrm{n}^{\mathrm{o}}$ 1, 21 de dezembro de 1822). Realidade mais próxima nesse momento, visto que as tropas brasileiras estão fora das muralhas de Montevidéu: "En esta capital y sus imediaciones, á donde no alcanza el influjo del despotismo imperial, se ha pronunciado con una rapidez y generalidad asombrosa, ya la multitud de impresos que han circulado sin contradicción es una de las pruebas de aquel aserto." (La Aurora. 
Montevidéu, $\mathrm{n}^{\mathrm{o}}$ 1, 21 de dezembro de 1822). Portanto, aproveitando-se dos conflitos entre tropas do Brasil e Portugal, passou-se a questionar o futuro da Província Cisplatina, a liberdade e a independência dos orientais foram cogitadas e projetadas na região.

Para tanto, os argumentos a favor da ocupação do território oriental pelo Exército imperial são combatidos pela imprensa periódica praticamente em sua totalidade. A cisão entre Brasil e Portugal, como já observado, torna-se elemento fundamental nos discursos opostos a ocupação, estes poderiam ser tanto favoráveis a uma independência parcial quanto a liberdade completa da Província Cisplatina. Para os periodistas cisplatinos contrários a continuidade da dominação estrangeira, a permanência na região das tropas oriundas do Brasil era ilegítima, pois esta rompia com o pacto firmado entre a população da Banda Oriental e o governo lusitano. O Congresso Cisplatino marcou a anexação da região ao Reino português, e no momento em que os lusitanos não ocupassem mais a Banda Oriental, a soberania, no entendimento dos locais, voltaria às mãos da população. Esta postura e estes argumentos repetem os eventos de 1808-1810, quando na ausência e impossibilidade de governar de um Monarca, no caso Fernando VII (1784-1833), baseado no principio da retroversão da soberania, o povo voltaria a ter o poder de decisão sobre seu futuro. Neste caso, segundo o periodista, a população da Província Cisplatina supostamente teria optado por se desligar do Brasil e via a necessidade de uma assembleia em que tal atitude fosse oficializada perante D. Pedro (1798-1834) e as autoridades brasileiras, afinal:

Para aquella incorporacion [Congresso Cisplatino] se habia creido necesaria, siquiera, la sombra de una representacion nacional, y ahora para hacerla al nuevo imperio del Brasil, se tiene por bastante la voluntad del sindico manifestada por su digno representante Lucas José Obes. - Entonces al menos los habitantes estapefactos, parece que aprobaban todo con su silencio; pero ahora los cabildos de la campaña juran por solo la fuerza, y el de la capital con todos los ciudadanos abiertamente se resisten y declaran ante al cielo y los hombres que no quieren pertenecer al Brasil. - Entonces al menos uso el senõr Baron "de sugestiones y de su influjo sobre los empleados;" pero ahora solo se vale de la fuerza, las cárceles y espartriaciones de todo ciudadano que no creo en sus intereses. Entonces se nos prometia un porvenir venturoso, regidos bajo leyes constitucionales y sábias, y ahora solo se nos ofrece la muerte, desolación y vergonzosa esclavitud. (El Pampero. Montevidéu, n. $03,1^{\circ}$ de janeiro de 1823 ) 
Além da evidente alteridade Oriental em relação a qualquer invasor estrangeiro, é clara, nesse contexto, a diferenciação entre portugueses, antigos signatários do Congresso Cisplatino, e o Brasil, herdeiro político da região. Os primeiros estiveram presentes na região com a anuência da população e a exemplo do que ocorria com a própria Nação portuguesa auxiliaram para a regeneração da Banda Oriental, através de novas leis e com uma constituição moderna que levaria o progresso para aqueles que a cumprissem. Já os imperiais ao manterem com a ocupação não atenderam os interesses da população da Província Cisplatina, escutando apenas seus aliados, como Lucas José Obes (1782-1838). Desse modo, levaram para a região as piores características de um regime despótico, que não existia mais em Portugal, perseguindo seus opositores, explorando os recursos naturais e implantando na Banda Oriental um regime de opressão e espoliação. Em suma, para os redatores do periódico, os Orientais se tornaram escravos da política brasileira e da seguida retirada de recursos da região sem contrapartida alguma.

A tirania e o despotismo de D. Pedro em oposição às diferenças da ocupação lusitana e a política ilustrada de Portugal também são debatidas a partir do conflito entre as tropas brasileiras e portuguesas estabelecidas na Província Cisplatina. Para os redatores do E1 Pampero as beligerâncias não tratam apenas da independência do Brasil, mas também do futuro da região, visto que os valorosos soldados das tropas dos Voluntários Reais, que já haviam combatido ao lado do famoso General Wellington (1769-1852) na expulsão dos franceses de Portugal, lutam novamente contra um déspota invasor para impedir que a tirania e a política imperialista, agora do Brasil, se estabeleçam na região. Os soldados que compunham as fileiras lusitanas guerreavam em nome de uma nação livre, enquanto as tropas imperiais nada mais eram do que escravos a serviço de um monarca absolutista. Além desses elementos, no periódico é destacada a esperança de que acabado o conflito, Buenos Aires entraria em cena e os Orientais se uniriam aos portenhos, com o Prata unido e plenamente independente. A liberdade projetada era parcial: tratava-se de desvencilhar-se do Brasil, tomado como um usurpador e agressor, para unir-se aos irmãos ocidentais:

Felizmente los Voluntarios Reales, los ilustres compañeros del inmortal Welligton estorban con su presencia la entera ejecución de estos planes infernales, probándonos con su conducta la diferencia que existe entre los soldados de una nación libre y los esclavos de un tirano - Cuando ellos dejen nuestras playas, ya estarán nuestros hermanos de occidente prontos a sostenter nuestros derechos y 
libertades, y á segundar nuestros esfuerzos. ¡Orientales" no lo dudéis. ¡Viles aristócratas! Temblad. (El Pampero. Montevidéu, n. $03,1^{\circ}$ de janeiro de 1823 )

Ainda em relação à independência do Brasil, Santiago Vázquez, redator do periódico El Ciudadano, aponta os contrastes entre a posição brasileira quando defende a própria liberdade e as diferenças nas suas ações, tomadas como despóticas, na Província Cisplatina. Para Vázquez, em texto publicado na primeira edição do jornal, D. Pedro buscando a independência do Brasil fez valer os princípios do liberalismo, atendeu os desejos da população que supostamente queria separar-se de Portugal e argumentou em favor da independência, apontando que um país com a extensão e as riquezas do Brasil poderia e deveria ser livre, ao passo que na Província Cisplatina os apelos da população pela liberdade não foram atendidos e todos os movimentos a favor da independência foram reprimidos violentamente. Portanto, para o periodista os brasileiros têm atitudes paradoxais, ao mesmo tempo em que buscam libertar-se do domínio de outra Nação, ocupam e oprimem a Banda Oriental:

El gobierno del Brasil pretende emancipar aquel territorio y establecer su independencia, mientras empeña sus tropas en la ocupacion de esta provincia: allí hace valer la voluntad de los habitantes, mientras aquí sufoca la de los orientales: allí se quiere que las máximas liberales de legitimidad, mientras aquí no puden aducirse otros que la fuerza y la opresion, la sangre y el acero. A nosotros no toca el examen de la causa que aquel gobierno sostiene, ni deslindar se ella es de la mayoridad de los brasilienses: pero entretanto ¡qué contraste singular! ¡qué contradicción tan marcada de principios! (El Ciudadano. Montevidéu, $\mathrm{n}^{\circ} 01,1^{\circ}$ de junho de 1823)

A política imperialista e despótica dos brasilienses, sobretudo a ação de Carlos Frederico Lecor, na Província Cisplatina era um dos principais alvos dos ataques e das reclamações da imprensa periódica cisplatina. Segundo os jornais locais, o Barão de Laguna favorecia a elite montevideana - sua base de apoio nos primeiros anos da intervenção -, era condescendente com as grandes arriadas de gado do território oriental e além de dividir grandes porções de terra entre os militares aliados, fechava os olhos para as expropriações de terra dos estancieiros rio-grandenses na região do rio Negro. Para Antonio Díaz, Santiago Vázquez e Juan Francisco Giró, redatores do periódico El 
Pampero, contrário à dominação brasileira, nesse momento, 1823, "la Banda Oriental no es ya aquel emporio de riquezas que tanto exitaba su ambicion, sino un campo yermo y desolado", a ruína da base produtiva e econômica dos orientais se devia principalmente ao roubo de gado e muares, os redatores escrevem ironicamente que "los ganados que eran sus mas opimos frutos, han pasado como por encantamiento a poblar las regiones del Brasil". Embora seja impossível averiguar a veracidade destes números e se reconheça o exagero na contagem como um recurso retórico, o mesmo periodista afirma que "desde la ocupacion de este territorio se han extraido por varios puntos de la frontera 21 millones de animales entre bacas, caballos y mulas", buscando legitimar suas alegações e mais uma vez apontar as atrocidades cometidas pelos invasores, Díaz, Vázquez e Giró asseveram que a quantidade "no asombrará á los que antes hayan visitado nuestros campos y á los que conozcan la rapacidad de los continentales." (El Pampero. Montevidéu, $\mathrm{n}^{\mathrm{o}} 02,25$ de dezembro de 1822).

Após as revoluções de independência na América e a razão e as luzes terem alcançado em 1810 o continente, a ação de Lecor impôs um sistema ainda mais pesado de opressão e espoliação. Desse modo, a dominação brasileira é compreendida também como um retorno ao período colonial. É desse modo que o periódico La Aurora retratou a permanência do Brasil, recém-liberto do jugo Português, na Banda Oriental:

Despues que estos pueblos saliendo, como otros muchos, del error en que se les mantenía sacudieron en el año 810 , el yugo de la dependencia, y juraron sostenerla á costa del sacrificio de sus vidas y fortunas, intentar ponerles nuevos grillos, incomparablemente mas pesados y ominosos que los que entonces quebrantaron, sujetarlos á la dominación de los colonos brasilienses, que apenas han dado un paso fuera del caos de la ignorancia, y cuya ilustracion víene marchando tras nosotros un siglo, cuando medos; querer, como decimos obrar un retroceso semejante con la aplicacion de aquellos mismos principios es sin duda alguna el proyecto mas ridículo y peligroso que puede concebirse. (La Aurora. Montevidéu, ${ }^{\circ}$ 01, 21 de dezembro de 1822)

Além de enriquecer os aliados do Barão de Laguna, a política imperialista imposta na região teria o escuso objetivo de "obligarnos [os Orientais] á tomar las armas, para ver si honestamente podían encontrar un pretesto de asesinarnos, y suplantar una nueva población 
brasileira". Tal atitude seria um grande erro, visto que os Orientais resistiriam bravamente e conseguiriam expulsar do território todos os que praticassem a rapina das riquezas pertencentes aos locais. Contudo, D. Pedro é isento da responsabilidade sobre os acontecimentos na região, sendo Lecor o principal responsável, pois "si el gabinete del Janeiro conociese sus verdaderos intereses, lejos de querer mantenermos unidos á su carro deberia reanunciar á su injusta é infructuosa conquista." ( $E l$ Pampero. Montevidéu, $\mathrm{n}^{\circ}$ 02, 25 de dezembro de 1822). Dessa forma, o chefe administrativo e militar da Província Cisplatina, culpado também pelas derrotas de Artigas e pela organização do Congresso Cisplatino, era tido como o grande inimigo da independência dos Orientais, sendo o causador direto da desolação e ruína de todo o território.

Não obstante os excessos dos três periodistas, uma necessidade retórica no momento em que se buscava fortalecer os movimentos contrários à continuidade da existência da Província Cisplatina, a historiografia aponta o crescente descontentamento dos locais com a política de Lecor, inclusive da classe dirigente de Montevidéu que anteriormente havia dado sustentação para a política portuguesa na região. Entre as principais atitudes do dirigente da Província Cisplatina que contrariavam a oligarquia local estavam o protecionismo dos comerciantes portugueses estabelecidos em Montevidéu, a permissão da livre navegação brasileira nos rios da região e o favorecimento dos charqueadores do sul do Brasil em relação aos saladeiristas orientais. De acordo com Rosa Alonso Eloy e seu grupo de investigadores, a insatisfação dos antigos aliados do Barão de Laguna decorria de uma política que satisfazia objetivos do Brasil, ou seja, que não eram os seus, na região oriental, onde eram os habitantes. Reivindicações que alcançavam também os comerciantes espanhóis fixados na praça de Montevidéu, estes reclamavam dos direitos e privilégios que tinham no período colonial e que foram transferidos para o círculo de aliados de Carlos Frederico Lecor (Eloy, 1972).

A suposta violência e opressão praticadas pelos imperiais sob o comando de Carlos Frederico Lecor continuam ocupando espaço em praticamente todos os periódicos surgidos ao longo do ano de 1823 . A personalidade e a figura do Barão de Laguna - título recebido neste mesmo ano - materializam para os redatores todas as ações do invasor estrangeiro. Dentre estas práticas são comuns às referências aos pretensos maus tratos e ataques às esposas e filhos dos habitantes locais, ferramenta utilizada para chamar atenção dos leitores para a política vista como cruel do invasor. Como contrapartida é evidenciada a tenacidade 
da resistência e a valentia dos Orientais perante os carrascos oriundos do Brasil. Um exemplo dessas alegações é um poema publicado na edição de número sete do periódico La Aurora:

2. ¿No escuchais esos ecos terribles Qual bramidos de un tigre feroz, Que estremecen los montes vecinos

$\mathrm{Y}$ los valles con triste fragor?

Esos son, Ciudadanos valientes, Los berdugos de Carlos Lecor; Ellos viene á vuestros hogares A quitarnos la vida y honor. CORO.

3. ¿No lo veis de saña inflamados Son espadas infames vibrar. A las castas esposás violando, Y á sus hijos matar sin piedad? Ese sordo rugido que suena Sos cadenas que intentan ceñir $\mathrm{Al}$ cobarde que no profiriese Antes muerte que esclavo vivir.

(La Aurora. Montevidéu, $\mathrm{n}^{\circ} 07,1^{\circ}$ de fevereiro de 1823)

Como observado na citação, nesse processo de construção de diferenças e de apelos à união dos Orientais, a escravidão exerce papel fundamental. No sentido político, Portugal e posteriormente o Brasil impuseram à região oriental, a partir da intervenção de 1816 e da criação da Província Cisplatina, a servidão com a retirada de todas as riquezas e a opressão. No sentido social, o escravismo é veemente execrado tanto pelos periodistas oposicionistas a permanência do Império do Brasil na região quanto aos favoráveis a existência da Província Cisplatina. Em um artigo intitulado "Comercio de negros", publicado na edição de número cinco do jornal La Aurora, é condenado "este tráfico infame de la especie humana, contra el cual há declamado la filosofia con tanta vehmencia desde el siglo anterior", tal prática havia sido "abolido en este pais como en otros del nuevo mundo á proporción que los pueblos han ido abrazando la causa de la ilustracion y la humanidade", entretanto com a chegada dos portugueses e posteriormente a manutenção da dominação pelos brasilienses esse comércio foi "restablecido en Montevideo por efecto de una de las medidas liberales de la Lógia de los Aristrocratas." (La Aurora. Montevidéu, nº 05, 18 de janeiro de 1823). Associada ao atraso, a monarquia e opressão brasileira, em 
contraposição à ilustração e razão das novas repúblicas americanas, a escravidão se torna fundamental na alteridade brasileira em relação a ampla construção da orientalidade como elemento aglutinador de todos os nascidos na Banda Oriental.

São variados os textos em que o escravismo e o crescente número de cativos presentes na Província Cisplatina são condenados. No início do ano de 1822, quando os rumores quanto à independência do Brasil passaram a ser debatidos nas páginas da imprensa periódica cisplatina, o Pacífico Oriental de Montevideo, periódico declaradamente favorável à ocupação portuguesa, publicou um artigo que alertava quanto aos perigos da escravidão para a sociedade, os riscos de revolta, a exemplo do que havia ocorrido em Santo Domingo, e estabelecia uma comparação entre a utilização do trabalho compulsório de indígenas, que auxiliaram os criollos nas batalhas pela independência do Peru, e africanos, presentes em grande número em toda sociedade lusobrasileira, portanto oferecendo riscos para a população. Em polêmica com o Argos de Buenos Aires

el pacífico oriental no quiere ni de (y aborrece al que esto quiera), levantar obra mala, lejos de eso apetece edificar un sólido y suntuoso edificio por medio de la union del Brasil con Portugal! porque conoce que no son lo mismo los africanos, que los indios para trabajar por la libertad civil. de aquel modo pues se evitan esos. horrores que amenazan á tan basto como rico territorio. por lo mismo desea fuera de la union todas las causas que puedan falsificar sus justos temores, y quisiera verlas realizadas ya. Usted debe saber muy bien que los indios en Perú han suplido la falta de las grandes máquinas para levantar y conducir enormes y pesadas masas á toda distancia, sin mas sueldo que el de su íntimo desco por la Libertad: que despues de la desgraciada jornada de Vilcapueyo de que hablaremos mas estensamente se desnudaron de los mas necesario para su subsistencia. por enriquecer al egército reunido en Marcha, y que en Ayoma concurrieron poderosamente á la salvación del general y de muchos oficiales los indios y los cochabambinos; esto es lo que jamas han de hacer los negros porque la experiencia acredita constantemente sus incitaciones, y por eso es que tememos males para El Brasil. (Pacifico Oriental de Montevidéu. Montevidéu, $\mathrm{n}^{\circ}$ 11, 02 de março de 1822)

Além dos riscos de rebeliões e ataques à população que uma sociedade escravista sofre constantemente, como alertado nas páginas do Pacífico Oriental de Montevideo, e do atraso político e social da 
manutenção da escravidão pelos aristocratas brasileiros como propagado nos textos de Antonio Díaz no periódico La Aurora, a crítica à violência e o caráter desumano da escravidão também estava presentes nos periódicos cisplatinos. Manuel Torres, proprietário e redator do jornal El Patriota, um dos mais comedidos articulistas do período, condena a presença dos cativos em Montevidéu e a forma que são tratados, uma prática tomada como comum e habitual pelos portugueses e que seria, na sua avaliação, mantida pelo Império do Brasil:

Ignoramos hasta que tiempo se extienden las facultades del gobierno portugues para extraer africanos: sin embargo no podremos negar que se ha conmovido nuestra sensibilidad, al ver á las puertas de algunas casas y almacenes de esta ciudad bastante número de aquellos desgraciados, en calidad de fardos de venta, con solo sola la diferencia de hallarse sentados como hombres. (El Patriota. Montevidéu, $\mathrm{n}^{\circ}$ 05, 13 de setembro de 1822)

Seguindo esta mesma linha argumentativa, Lucas José Obes, integrante do "Clube do Barão" e figura fundamental tanto na incorporação da Banda Oriental em 1821 quanto na adesão da Província Cisplatina à independência do Brasil no ano seguinte, advoga em defesa de duas escravas, Mariquilla e Encarnación, que assassinaram sua proprietária, Celedonia Wich, uma rica viúva, em Montevidéu. O advogado inicia suas alegações questionando um povo e um local "donde el color de las personas passa por signo de esclavitud o libertad, donde las amas creen que el siervo es uma bestia de carga, y las leyes no lo desmienten." As arguições seguem discorrendo sobre as origens da escravidão, as diferenças entre a prática na antiguidade e naquele momento, e defendem os cativos, afinal "los esclavos sienten, los esclavos gimen; hay padres entre ellos, hay maridos, hay amantes, hay personas de un temperamento flerte, de una alma noble, de um carácter bello, pero no servil." Obes destaca igualmente que a atitude tomada pelas duas escravas assassinas não foi sem motivações, pois "ella [Celedonia Wich] era cruel, era bárbara para com sus esclavas... se sabra que su alimiento era escasso: el vestido malo, el trabajo mucho, la opresión constante." (Pintos, 1996, p. 184-188). Embora o objetivo de livrar Mariquilla e Encarnación da pena não tenha sido atingindo - ambas foram executadas no dia 02 de abril de 1824 -, José Lucas Obes produziu um ótimo texto de combate à escravidão na Província Cisplatina e demonstrou que mesmo a classe dirigente que apoiava e se aproveitava da presença do Brasil na região, condenava a escravidão e de alguma forma se afastava e diferenciava dos imperiais. 
Esta justaposição entre periódicos e figuras importantes da política da Província Cisplatina que comitantemente apoiam a ocupação do Brasil e condenam o caráter escravista de sua sociedade é comum, na mesma medida que jornais que se posicionam frontalmente contra os imperiais e condenam a escravidão, tem nas suas páginas avisos de compra e venda de cativos. Um exemplo dessa postura pode ser encontrado no periódico El Pampero ao anunciar a venda de uma jovem escrava aos possíveis interessados, contudo entre seus três redatores está Antonio Díaz, redator do La Aurora que, como já observado, dezessete dias depois vai atacar o caráter desumano da escravidão. Na seção de avisos do jornal está o seguinte anúncio:

Quien quisiere comprar una negra de catorce años de edad, sin vicios, sabe lavar, planchar, y los demas servicios domesticos, se servirá hablar con el Mayor de Brigada de Caballeria de la Division de los Voluntarios Reales del Rey residente en la casa de d. Antonio Baltasar Perez en el Arroyo Seco; siendo su costo 350 pesos. (El Pampero. Montevidéu, $\mathrm{n}^{\circ} 03,1^{\circ}$ de janeiro de 1823 )

Não obstante ao crescimento do número de cativos durante os anos de existência da Província Cisplatina, o historiador uruguaio Alex Borucki aponta que entre os anos de 1778 e 1810 mais de cinquenta mil escravos oriundos da África ou do Brasil desembarcaram no rio da Prata. O porto de Montevidéu foi responsável por receber grande parte desse contingente de cativos que posteriormente eram internados e distribuídos em toda região platina (Borucki, 2011, p. 81-107). O tráfico destes escravos que chegaram ao Prata era de responsabilidade principalmente de comerciantes luso-brasileiros. Como lembra Fabrício Prado, as relações entre os comerciantes estabelecidos na Banda Oriental, sobretudo em Montevidéu, com a América portuguesa eram organizadas e estáveis, mesmo que em alguns momentos fossem realizadas na ilegalidade. Dados que demonstram apesar da crítica sobre a presença de escravos durante a vigência da ocupação do Brasil, a existência de cativos e de comerciantes de escravos oriundos do mundo lusitano não era novidade aos olhos dos Orientais que participavam e incentivavam tal prática desde os séculos anteriores (Prado, 2010, p. 76).

Em relação à presença de escravos na Província Cisplatina, principalmente na região norte, local das grandes estâncias de gado e de maior presença de rio-grandenses, Eduardo Palermo oferece subsídios significativos. Através da análise de dados dos censos realizados 
em 1822 e 1824 na região ${ }^{4}$, o historiador indica que nos distritos de Paysandú, Tacuarembó e Cerro Largo e suas respectivas jurisdições, em termos de porcentagem do número de cativos em relação aos homens e mulheres livres as proporções são as maiores da Província Cisplatina, com as cifras alcançando os $31 \%$, chegando a taxa de $75 \%$ das estâncias possuírem ao menos um trabalhador escravo, em sua maioria de propriedade de luso-brasileiros. Na cidade de Montevidéu, os números deveriam superar estas taxas, pois era o porto de entrada de novos escravos, contudo os censos não contabilizam a população flutuante, caso da capital, e sim os habitantes registrados, a exemplo da região fronteiriça. Estabelecendo uma relação com a província mais próxima e que tinha intensa movimentação nas fronteiras, Eduardo Palermo afirma que "en la década de 1820, los porcentajes de población esclavizada en el norte uruguayo y Rio Grande do Sul son similares, constituyendo la Banda Norte una verdadera prolongación socio-económica de los territorios rio-grandenses." Posição que reafirma as reclamações de Orientais em relação a política de favorecimento de rio-grandenses na fronteira, a ocupação de terras e o roubo de gado da Província Cisplatina sem o controle das autoridades locais (Palermo, 2008, p. 300).

Em alguns periódicos, a exemplo do El Aguacero, a reprovação da ocupação brasileira, conjuga todos os componentes já citados, a opressão, a monarquia, o atraso político e a escravidão, política e/ou social. Estes elementos, mais uma vez tornam o invasor o inimigo em comum que deve ser combatido, se necessário até a morte, para cumprir o destino inequívoco dos Orientais, a liberdade, embora não seja anunciada se parcial ou total:

Vuestros pérfidos planes tenebrosos

Cayeron para siempre, triunfó el cielo

Del amante del bien, y en triste duelo

Gimen los parricidas ominosos.

¿Qué os resta pues?... abandonad la tierra,

\footnotetext{
${ }^{4}$ Com objetivo de controlar a população cisplatina, principalmente em relação a polêmica com exdonatários de terras do período artiguista foi determinado em 07 de setembro de 1821 instruções para a realização de censos em todas as jurisdições da província. Como lembra o próprio Eduardo Palermo, os dados dos censos são fragmentados e incompletos, haja vista que em poucas localidades foi possível fazer o levantamento completo e, ainda, é necessário questionar algumas das informações fornecidas pelos entrevistados: "Si bien la mayoría de los censos adolecen de sérios defectos en la recolección de datos, debido a la imprecisión de quienes son encargados de recogerlos y al ocultamento de información por parte de los encuestados - existía el temor de revelar la información correcta debido a posibles cargas impositivas o para sustentar el ejército -, ellos permiten aproximarnos a una realidad bastante diferente de la que se ha proyectado al presente." (Palermo, 2008. p. 285)
} 
Id donde los esclavos - el Oriente

Declara á los tiranos cruda guerra:

Yugos, cadenas, grillos no consiente,

Su corage á los déspotas aterra,

Y eleva su destino INDEPENDIEMTE

(El Aguacero. Montevidéu, nº 02, 26 de abril de 1823)

Com o início da Guerra da Cisplatina, a atividade periodística diminuiu substancialmente. Todavia, os jornais que surgiram durante o conflito continuam apontando a resistência dos Orientais em contraposição ao despótico regime brasileiro. Em Canelones, ponto de resistência das tropas lideradas por Juan Antonio Lavalleja (17841853), surge o jornal que é considerado pela historiografia nacionalista o primeiro periódico da história do Uruguai, justamente pela defesa irrestrita da independência, a Gaceta de la Provincia Oriental (Lucuix, 1943 , p. 20). No jornal as notícias sobre o conflito seguem o mesmo arranjo, "los esclavos del Emperador del Brasil" atacam e exploram a população da Província Oriental, insultando "el pabellon de la Republica." (Gaceta de la Provincia Oriental. Canelones, n 01, 14 de novembro de 1826).

Outra forma de diferenciação entre os brasilienses e os Orientais é a maneira com que as notícias e os editoriais sobre o Brasil foram publicados no jornal. Enquanto os assuntos locais têm destaque e a província permanece nomeada como Banda Oriental, na seção "exterior" é veiculada a informação da chegada de novos contingentes de soldados ao "território limítrofe" da província de São Pedro do Rio Grande do Sul. O texto também evidencia a suposta desorganização das tropas do Império do Brasil na fronteira: "por indivíduos llegados recientemente de Puerto Alegre y Río-Grande sabemos, á no dudarlo, que el egército enemigo se encuentra completamente desorganizado, y que todas las tropas divididas en la frotera no llegan al número de seis mil hombres." Tal estado de desordem e ineficácia do exército brasileiro já deveria ter acabado com a guerra, porém "los gefes brasileros han tenido la suerte, que con poco de ménos ignorancia debierou esperar del despota europeu que los domina." (Gaceta de la Provincia Oriental. Canelones, $\mathrm{n}^{\mathrm{o}}$ 02, 21 de novembro de 1826). No mesmo trecho, os redatores da Gaceta de la Provincia Oriental tratam os invasores como estrangeiros, embora estes ainda permanecessem nas duas maiores cidades da região e todo o território pertencesse a Província Cisplatina sob o comando do Brasil, e destacam a ineficácia militar de homens que não lutam por um ideal ou pelo patriotismo e sim por serem compelidos por um déspota europeu, 
em antítese ao americanismo das repúblicas vizinhas, monarca tomado como ignorante e opressor, que não domina apenas os Orientais mas também os próprios habitantes do Brasil.

Além de D. Pedro, "Neron del Continente Americano" (Gaceta de la Provincia Oriental. Canelones, $n^{\circ}$ 01, 14 de novembro de 1826), o alvo preferencial das páginas dos periódicos cisplatinos continuava sendo Carlos Frederico Lecor. Na edição de número quatro da Gaceta de la Provincia Oriental foi publicado na íntegra um comunicado do Barão de Laguna destacando a proteção pelas armas brasileiras das fronteiras e das propriedades dos rio-grandenses frente aos supostos ataques das milícias da Província Oriental, contudo antes a publicação adverte que a proclamação é "tan fria como su sangre [Lecor], y tan hipócrita como su caracter, e dessa forma "no tiene otro objeto que iludir á los habitantes de la frontera y del Rio-grande, manifestandoles el grande interes y empeño con que toma la defensa de sus haciendas, que supone amenazadas por la marcha de nuestro egèrcito." É significativo notar que no documento reproduzido no jornal, o governador da Província Cisplatina, em meio ao conflito armado, não se dirige aos imperiais ou aos Orientais e sim ao povo "CISPLATINO: los reiteramos clamores de los hacendados de esta campaña vienem de nuevo á implorar de nuestras armas, uma justa protecion que ellas van ofrecerles sin trepidar", atitude necessária "en vista de tamãnos atentados"(Gaceta de la Provincia Oriental. Canelones, $\mathrm{n}^{\circ}$ 04, 12 de dezembro de 1826) cometidos pelos milicianos. Buscando o apoio da população local, sobretudo de Montevidéu, o comandante do exército e da administração pública na Província Cisplatina, não apela a ligações identitárias e sim à pacificação e à proteção das riquezas da população, retornando ao mesmo discurso de anos anteriores, quando se buscava a legitimação da ocupação lusitana no mesmo local.

Foi possível destacar os diferentes momentos e as distintas formas que a alteridade brasileira apareceu nas páginas dos periódicos da Província Cisplatina. No período imediatamente posterior a oficialização da dominação lusitana na região, a incipiente imprensa periódica ainda tratava genericamente portugueses e brasileiros, nos textos buscava-se legitimar a dominação estrangeira, afinal mesmo que a região estivesse provisoriamente em domínio de outra nação, acreditava-se que apenas dessa forma seria possível alcançar a pacificação e a regeneração política e social. Com o processo de independência do Brasil, e principalmente a permanência das tropas na Província Cisplatina, passou-se a questionar a presença dos Brasilienses, já que o pacto político fora assinado com os portugueses e nesse momento não teria mais validade. Desse modo, os 
brasileiros (referenciados também como brasilienses e imperiais) foram tomados como invasores, despóticos e opressores dos Orientais, os abusos contra os habitantes da região e a espoliação das riquezas foram seguidamente tema de longos textos dos diferentes periódicos contrários ao Brasil. Entretanto, foi na escravidão que a alteridade brasileira foi mais utilizada para destacar a diferenciação oriental. Portanto, o Brasil representava a corrupção, a monarquia e o escravismo, tudo o que uma identidade americana, tanto Oriental quanto portenha renegava e forneceu subsídios para se negar a ocupação brasileira e se buscar a independência, parcial ou total.

\section{Referências}

\section{Fontes:}

Periódicos da Biblioteca Pablo Blanco Acevedo pertencente ao acervo do Museu Histórico Nacional (Montevidéu):

- Pacífico Oriental de Montevidéu 1821-1822;

- El Patriota. Montevidéu, 1822;

- El Aguacero. Montevidéu, 1823;

- El Pampero. Montevidéu, 1823;

- El Pampero. Montevidéu, 1823;

- La Aurora. Montevidéu, 1823;

- El Ciudadano. Montevidéu, 1823;

- Gaceta de la Provincia Oriental. Canelones, n. 02, 21 de novembro de 1826.

\section{Bibliografia}

ANDERSON, Benedict. Comunidades imaginadas: reflexões sobre a origem e a difusão do nacionalismo. São Paulo: Cia das Letras, 2008.

BALAKRISHNAN, Gopal (Org.). Um mapa da questão nacional. Rio de Janeiro: Contraponto, 2000.

BARRÁN, José Pedro; FREGA, Ana; NICOLIELLO, Mónica. El Cónsul britânico en Montevideo y la independencia del Uruguay. Selección de los informes de Thomas Samuel Hood (1824-1829). Montevideo: Dpto. de Publicaciones de la UdelaR, 1999.

BORUCKI, Alex. The Slave Trade to the Río de la Plata. Trans-imperial Networks and Atlantic Warfare, 1777-1812. In: Colonial Latin American Review, New York, v. 20, n. 1, p. 81-107, Apr. 2011.

CHIARAmOnTe, José Carlos. Cidades, Províncias, Estados. Origens da nação Argentina (1800-1846). São Paulo: Hucitec, 2009.

CHIARAMONTE, José Carlos. Formas de identidad en el Rio de la Plata luego de 1810. In: Boletín del Instituto de Historia Argentina y Americana "Dr. E. Ravignani”, Buenos Aires, $3^{\mathrm{a}}$ serie, n. 1, p. 71-92, $1^{\text {o }}$ sem. 1989.

FREGA, Ana. Pueblos y soberania em la revolucion artiguista. La región de Santo Domingo Soriano desde fines de la colônia a la ocupacíon portuguesa. Montevidéu: Ediciones Banda Oriental La República, 2011. 
GALEANO, Eduardo. As caras e as máscaras. Porto Alegre: L\&PM, 2010. (Memória do fogo, 2).

HOBSBAWN, Eric J. Nações e nacionalismo desde 1780. Programa, mito e realidade. 5. ed. Rio de Janeiro: Paz e terra, 2008.

ISLAS, Ariadna. Límites para un Estado. Notas controversiales sobre las lecturas nacionalistas de la Convención Preliminar de Paz de 1828. In: FREGA, Ana (Coord.). Historia Regional e Independencia del Uruguay. Proceso histórico y revisión crítica de sus relatos. Montevideo: Ediciones de la Banda Oriental, 2011.

JANCSÓ, István; PIMENTA, João Paulo. Peças de um mosaico (ou apontamentos para o estudo da emergência da identidade nacional brasileira). In: MOTA, Carlos Guilherme (Org.). Viagem incompleta. A experiência brasileira (1500-2000). São Paulo: Ed. SENAC, 2000.

PALERMO, Eduardo. Tierra Esclavizada. El Norte uruguayo en la primera mitad del siglo 19. Dissertação (Mestrado) - Universidade de Passo Fundo, Passo Fundo, 2008.

PALTI, Elías José. La nación como problema. Los historiadores y la “cuestión nacional". Buenos Aires: FCE, 2002.

PIMENTA, João Paulo. Portugueses, americanos, brasileiros: identidades políticas na crise do Antigo Regime luso-americano. Almanack Braziliense (Online), São Paulo, v. 3, p. 69-80, 2006.

PINTOS, Aníbal Barrios. Historias privadas de la esclavitud: un proceso criminal en tiempo de la Cisplatina. In: BARRÁN, José Pedro; CAETANO, Gerardo; PORZECANSKI, Teresa. Historias de la vida privada en el Uruguay. Entre la honra y el desorden 1780-1870. Montevidéu: Taurus, 1996.

PRADO, Fabrício. A presença luso-brasileira no Rio da Prata e o período cisplatino. In: NEUMANN, Eduardo Santos. GRIJÓ, Luiz Alberto. O Continente em armas: uma história da guerra no sul do Brasil. Rio de Janeiro: apicuri, 2010.

REAL DE AZÚA, Carlos. Los orígenes de la nacionalidad uruguaya. 2. ed. Montevideo: Arca, 1991.

RENAN, Ernest. Qu'est-ce qu'une nation? In: Discours et conférences. Paris: CalmannLévy, 1887.

RIBEIRO, Fábio Ferreira. O general Lecor e as articulações políticas para a criação da Província Cisplatina: 1820-1822. Dissertação (Mestrado em História Social) Instituto de Filosofia e Ciências Sociais, Universidade Federal do Rio de Janeiro, Rio de Janeiro, 2007.

THIESSE, Anne-Marie. Ficções criadoras: as identidades nacionais. In: Revista Anos 90, Porto Alegre, v. 1, n. 15, p. 7-23, 2002. 